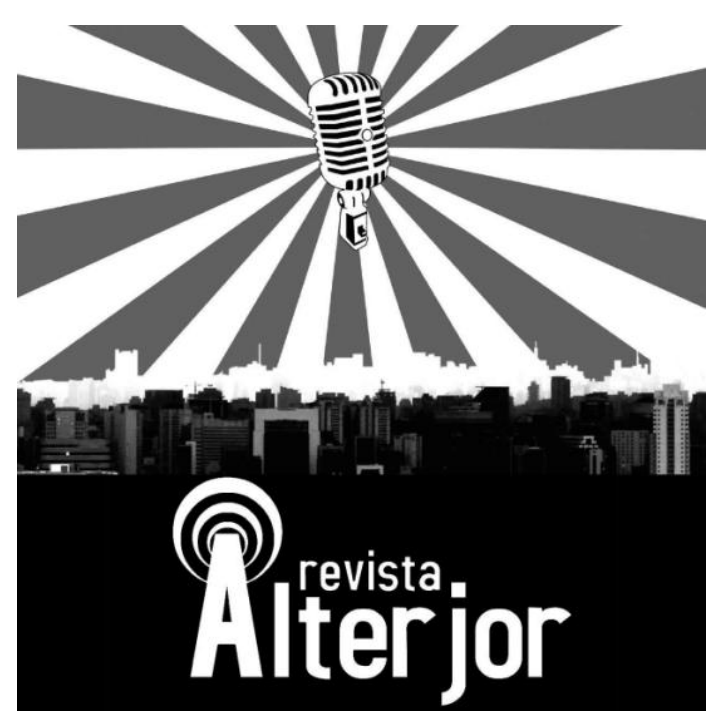

\title{
ESTRANGEIROS LOCAIS: MOBILIDADE ROMPIDA PELA SEGREGAÇÃO SOCIORRACIAL URBANA
}

Ana Clara Gomes ${ }^{1}$

RESUMO: A cidade depende da movimentação que os meios de transportes a oferece para garantir a circularidade dos fluxos da vida urbana. O deslocamento de pessoas é necessário para que haja um movimento de integração na cidade. Os meios de transportes, entretanto, também podem segregar, quando funcionam como dispositivo de controle social. Se a mobilidade urbana é interrompida, temse fronteiras aos estrangeiros locais, impossibilitados de vivenciar a cidade. Vigiados e punidos, os estrangeiros locais têm o consenso do Estado, da polícia, do discurso midiático e da classe dominante para protagonizarem uma segregação sociorracial urbana. Por serem negros e pobres, os estrangeiros locais são proibidos de desfrutarem das praias da Zona Sul do Rio de Janeiro, de sua própria cidade.

PALAVRAS-CHAVE: Processos comunicativos. mobilidade urbana. segregação urbana. racismo.

ABSTRACT: The city depends on the movement that the means of transport offers to guarantee the circularity of the flows of urban life. The displacement of people is necessary for there to be an integration movement in the city. The means of transport, however, can also segregate, when they function as a device for social control. If urban mobility is interrupted, there are boundaries for local foreigners, unable to experience the city. Guarded and punished, local foreigners have the consensus of the State, the police, the media discourse and the ruling class to lead an urban socio-racial segregation. Because they are black and poor, local foreigners are forbidden to enjoy the beaches in the South Zone of Rio de Janeiro, in their own city.

KEYWORDS: Communicative processes. urban mobility. urban segregation. racism.

\footnotetext{
${ }^{1}$ Doutoranda em Comunicação e Cultura, pela Escola de Comunicação da Universidade Federal do Rio de Janeiro (UFRJ), mestra em Comunicação e Cidadania pela Universidade Federal de Goiás (UFG), especialista em Patrimônio, Direitos Culturais e Cidadania e jornalista graduada pela UFG. E-mail: anaclagc@hotmail.com
}

Revista ALTERJOR

Grupo de Estudos Alterjor:Jornalismo Popular e Alternativo (ECA-USP)

Ano 10 Volume 02 Edição $22 \quad$ Julho-Dezembro de 2020

Avenida Professor Lúcio Martins Rodriģues, 443, Cidade Universitária, São Paulo, CEP: 05508-020 


\section{Introdução}

Por emaranhados de fluxos, rastros e processos, a cidade constrói-se e se reconstrói constantemente. Entender que o contínuo cruzamento de pessoas, de histórias, de culturas, de espaços, de subjetividades e de materialidades convergem-se e formam um lugar comum de vida, alocado na cidade, é um passo importante para assimilar a fluidez da vida urbana e seu excepcional poder de transformação. Para Deleuze \& Guattari (1997), a cidade é correlata da estrada e, por assim ser, só existe em razão de uma circulação e de seus circuitos; ela se constitui com entradas e saídas. Em diálogo com os autores, a cidade, na perspectiva de Caiafa (2007), é marcada por movimento e deslocamento, cujos fluxos que vêm de fora - e também os de dentro criam um nomadismo tipicamente urbano e constituem a cidade como lugar tanto de circulação quanto de dispersão. A cada movimento, a cada mobilidade e migração com suas chegadas e partidas, a cada ocupação, a cada inovação tecnológica, a cada decisão política e a cada fenômeno socioeconômico, muda-se a cidade, novas fronteiras são realocadas e, assim, novos processos de exclusão, também, são estabelecidos.

No limiar entre o crescimento urbano e a territorialização e reterritorialização da cidade, se dá a divisão espacial e simbólica dos lugares que podem ou não ser habitados ou, simplesmente, frequentados, de acordo com relações de poder. A desigualdade social é nitidamente expressa nas formas de ocupação da cidade, bem como na ausência desta em detrimento de gênero, raça, etnia ou classe, e marca o confronto urbano de pertencimento e não pertencimento a lugares de fala, a lugares de direitos e a lugares de significação social. Os contrastes da relação ausência, presença e pertencimento são incontáveis, mas demasiadamente notórios e expressos nos mais corriqueiros elementos da cidade; são evidenciados em todas as esferas públicas da vida social, da saúde à educação, da moradia à mobilidade urbana.

Uma vez que a condição de cidadão, habitante e pertencente à cidade, pressupõe liberdades individuais dos direitos civis, a cidadania está intrinsecamente relacionada ao direito de ir e vir, à liberdade de deslocamento dentro do espaço urbano e à liberdade de ocupação da cidade das mais diversas e subjetivas maneiras possíveis. Deslocar, 


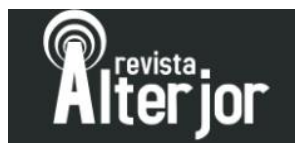

transladar, transportar são, portanto, ações significativas e elementares que mantêm o movimento vivo da cidade e que garantem a circularidade das redes e fluxos. Se não há transporte e movimento, não há trocas, não há comunicação, não há integração, não há mudanças na cidade. São os meios de transportes que instrumentalizam e tornam possível o ir e vir a longas ou curtas distâncias, otimizando sempre a relação espaçotempo. São eles - sobretudo o transporte coletivo - que permitem a mobilidade urbana e, assim, a interconexão de pessoas de diferentes lugares a diferentes locais de encontro, seja por qual motivo necessite-se deslocar e presenciar novos espaços. Como um meio de transporte mais democrático, o transporte coletivo

\footnotetext{
É um grande agente dos desafios da cidade porque constrói acesso aos lugares e pode criar em seu meio mesmo um tipo de ocupação coletiva do espaço urbano. [...] O transporte coletivo, ao distribuir de alguma forma a população, ao conduzir para longe das vizinhanças, tem um aspecto dessegregante. Ocorre uma dessegregação, mesmo que provisória e local. $\mathrm{O}$ transporte coletivo reúne à sua maneira desconhecidos e dispersa a população, realizando por si só uma abertura (CAIAFA, 2007, p. 119).
}

Trabalho, estudo, lazer, moradia, busca por serviços. Todas essas instâncias da vida social pressupõem uma necessidade de chegada e partida que, por sua vez, dependem do percorrer distâncias. Estas que, com o desenvolvimento tecnológico e o uso do maquínico a serviço de pessoas, podem ser encurtadas e facilitadas. Da bicicleta ao avião, os meios de transportes são indispensáveis nas sociedades modernas, de tal forma que sua ausência é impensável, inestimada e inadmissível na urbanidade. Entretanto, como componente elementar da vida na cidade grande, eles também se inserem na complexa lógica dos processos de exclusão e segregação, mesmo em se tratando de transporte coletivo com seu caráter elementar de dessegregante.

\section{A mercantilização do ir e vir}

Para além da globalizante necessidade de deslocamento e locomoção, a questão da mobilidade urbana se encaixa, em primeira instância, na relação binária público 


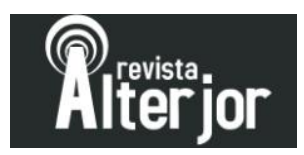

versus privado, estabelecida, sobretudo, quando as concessões do transporte público são fornecidas ao domínio de empresas privadas para implementação, funcionamento e manutenção do transporte coletivo como opção para a circulação de pessoas, como ocorre na cidade do Rio de Janeiro ${ }^{2}$. A liberdade individual do ir e vir, expressa na Declaração Universal dos Direitos Humanos, e a ideia de ser "livre a locomoção no território nacional em tempo de paz, podendo qualquer pessoa, nos termos da lei, nele entrar, permanecer ou dele sair com seus bens", expressa no artigo $5^{\circ}$, inciso XV da Constituição Federal de 1988, ficam, assim, à revelia da mercantilização do transporte público e da condição financeira de se arcar ou não com o serviço prestado. Tida como um grande negócio, a locomoção no espaço urbano e o direito ao transporte, transcendem a condição de um direito social ${ }^{3}$, fruto do estado de direitos, e passam a protagonizar a emblemática do transporte público e coletivo, nas grandes cidades, que atua, primeiramente, no palco da lucratividade e dos interesses da iniciativa privada.

Deve-se, portanto, criticizar o uso do transporte público, reiterando as suas falhas e limitações em articulação aos seus alcances, a sua abrangência e desempenho, considerando sempre os interesses econômicos das empresas que o operam. De fato, partindo da perspectiva de Lemos $(2009$, p. 29) a "mobilidade deve ser politizada. [...] Ela não é neutra e revela formas de poder, controle, monitoramento e vigilância, devendo ser lida como potência e performance”. Não há neutralidade na constatação de que a mobilidade é restrita aos que têm condições socioeconômicas de alcançá-la; não há neutralidade em saber que a mobilidade de uns só existe em razão da imobilidade de outros, ainda segundo o autor; não há neutralidade em perceber que o interesse público da locomoção é, em geral, sobreposto pelo interesse privado dos lucros empresariais; e, por fim, não há neutralidade ao não se desvincular a mobilidade do mercado econômico, do mercado de trabalho formal, em que o alcance dos transportes públicos às áreas

\footnotetext{
2 “A prefeitura do Rio de Janeiro anunciou a intenção de realizar uma licitação geral das linhas de ônibus da cidade. [...] Uma mudança fundamental era a que alterava a relação do poder concedente (prefeitura) com as empresas de ônibus, que deixaram de ser permissionárias para se tornarem concessionárias" (MATELA, 2014, p. 163).

${ }^{3}$ De acordo com o portal de notícias do Senado, no dia 15 de setembro de 2015 , foi promulgada, no Congresso Nacional, a PEC 74/2013, que institui o transporte como direito social no artigo $6^{\circ}$ da Constituição Federal.
} 


\section{Aireior}

urbanas delimita locais que podem ou não ser frequentados, por quais grupos e em quais períodos do dia.

Para além da relação dicotômica mobilidade versus imobilidade, podemos também incluir, em uma análise da restrição e limites dos meios de transporte, a questão das expectativas e finalidades de uso deles para a locomoção, também relacionando o tipo de veículo e tecnologias utilizados. Imagina-se, desta forma, determinado grupo social com condição financeira de arcar com o serviço de deslocamento por meio de um helicóptero, de um avião, ou mesmo de um carro particular, para fazer uma viagem a lazer, por exemplo, em favor de determinados grupos sociais que precisam utilizar de bicicleta, ônibus, ou metrô para se deslocar ao trabalho, por exemplo. Os meios de transportes demandados e utilizados por grupos de maior poder aquisitivo apresentam uma presteza técnica e tecnológica que os colocam em um sistema de funcionamento eficiente e com menos probabilidade de falhas ou soluções rápidas para qualquer inconveniente. Já os meios de transportes utilizados pelas populações de baixo poder aquisitivo, principalmente em se tratando de transporte público, têm uma predisposição maior à lentidão, às condições adversas e à possibilidade de falhas sem soluções rápidas. Isso, evidentemente, em um quadro de proporcionalidade. O assunto fica bastante sério quando o uso dos meios de transporte da instância pública não é uma escolha e sim a única opção para interconectar pontos espaciais distantes no qual se desenvolvem a vida social.

Há de se notar que as relações técnicas são parte das relações sociais de poder que culminam em contradições no desenvolvimento tecnológico, na perspectiva de Gonçalves (2006). Para ele há uma tensão constante entre tecnologia e território. E essa tensão expressa-se na forma como os meios e os tipos de transportes instituem fronteiras do acessível para uns e do inacessível para outros. Eles

Implicam em mobilidades constrangidas por imobilidades infraestruturais e dificuldades de acesso e de deslocamento. A mobilidade de uns se dá também em função da imobilidade de outros, já que existem diferentes graus de mobilidade que expressam diferentes poderes e controles contemporâneos (tipos de acesso a máquinas, redes, espaços físicos, espaços culturais, linguísticos...). Diferentes 


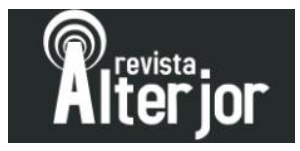

mobilidades refletem diferentes hierarquias e geografias de poderes (LEMOS, 2009, p. 29).

A tensão tecnologia e território gera a tensão mobilidade e fronteira, que, por sua vez, incita à relação de poder e acesso. Recorremos a alguns questionamentos: se o espaço urbano se abre, ou, pelo menos, deve-se abrir, a todos, por que a mobilidade é territorializada? Por que há zonas em que a circulação é de privilégio de carros particulares e inacessível ao transporte público? Como os meios de transporte são seccionados também pelas condições sociorraciais e como essas condições influenciam no deslocamento de pessoas a determinados lugares? Não há respostas incisivas sobre essas questões. Entretanto são questionamentos que devem servir para uma crítica reflexiva sobre os processos de exclusão e de segregação evidenciados pela ordem socioeconômica e sociorracial na cidade, que também se manifestam nos meios de transportes.

\section{Estrangeiros de nossa própria cidade}

Se tomarmos como base a noção do termo estrangeiro trazida por Shutz (2010), consideraremos que a palavra se remete a um indivíduo que, o tempo todo, tenta ser aceito ou, minimamente, tolerado por um grupo do qual ele se aproxima, ou do qual ele já convive. A tentativa de inserção é acompanhada da sua restrição ao status de membro do grupo dominante e, desta forma, tal indivíduo "está inapto para alcançar um ponto de partida para tomar seus rumos" (SCHUTZ, 2010, p. 124). Os caminhos ou rumos citados podem se referir à ordem do cotidiano da vida urbana, no que concerne à aceitação social, à empregabilidade, à moradia, à alimentação, ao acesso à educação, à saúde e, também, ao acesso ao transporte público e ao direito de livre circulação e mobilidade. Portanto, qualquer pessoa que represente uma potencialidade ou característica marcante de um grupo minoritário, à margem da ordem socioeconômica e sociorracial dominante, ou à margem de modelos idealizados hegemonicamente, pode ser considerada como estrangeira. A jovem pobre que entra na universidade pelo sistema de cotas, o garoto interiorano que vai morar na cidade grande, o presidente negro que assumiu o comando nos Estados Unidos, a primeira mulher eleita para ser presidenta do Brasil, o morador de rua que vira um cantor famoso, a mulher que sustenta os filhos se prostituindo, a moradora de favela que enfrenta três ônibus para 


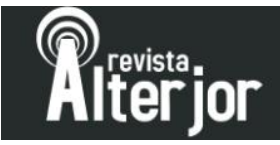

trabalhar, todo dia, na Zona Sul (Figura 1) do Rio de Janeiro, todos eles são estrangeiros numa perspectiva de contextos.

Figura 1. Mapa da cidade do Rio de Janeiro - bairros da Zona Sul

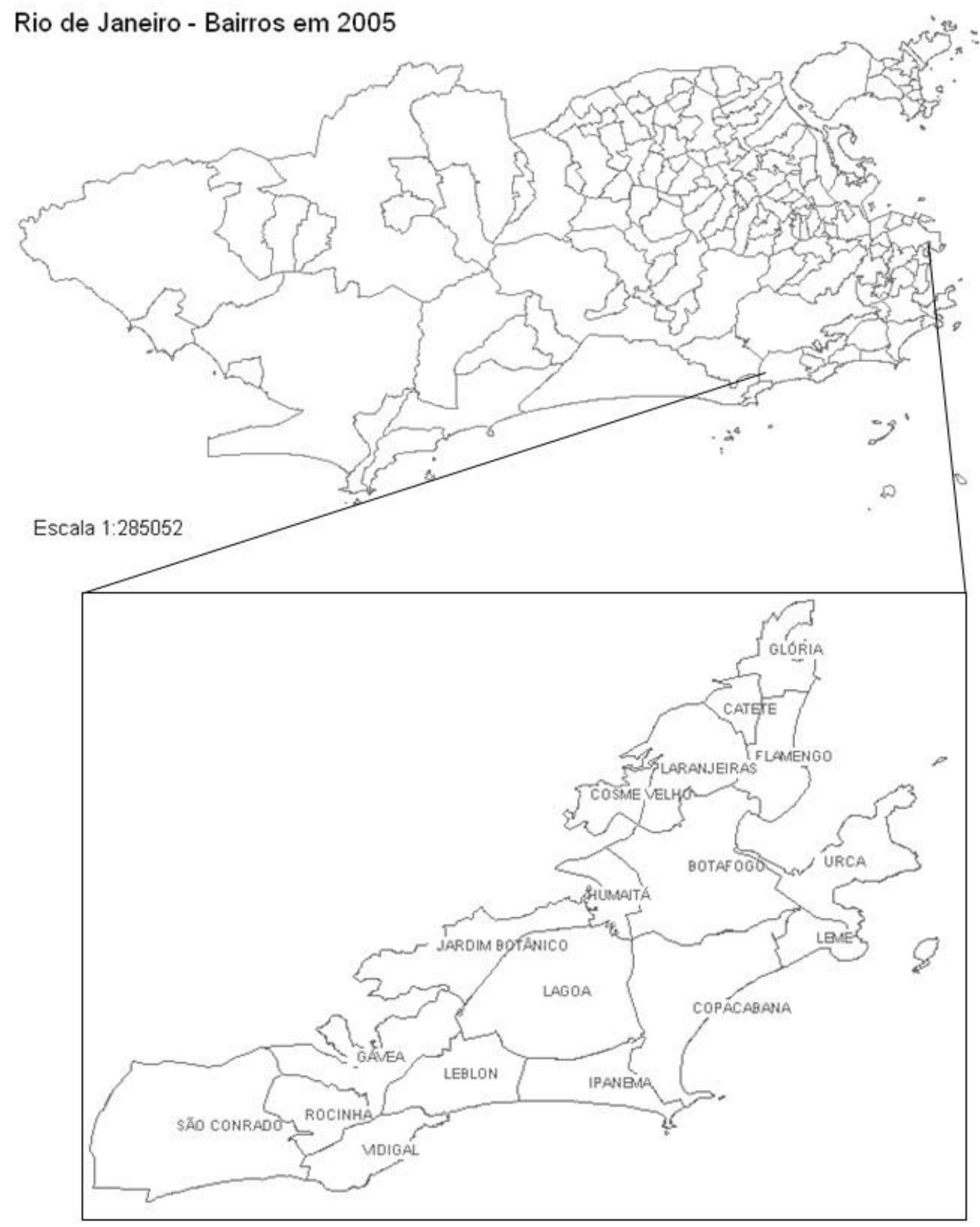

Fonte: SILVA, 2010, p. 68.

Revista ALTERJOR

Grupo de Estudos Alterjor:Jornalismo Popular e Alternativo (ECA-USP)

Ano 10 Volume 02 Edição $22 \quad$ Juho- Dezembro de 2020

Avenida Professor Lúcio Martins Rodriģues, 443, Cidade Universitária, São Paulo, CEP: 05508-020 


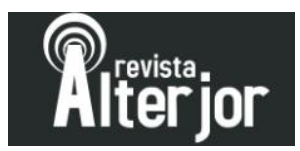

A noção de estrangeiro está intimamente relacionada à ideia de fronteiras, de territórios, de deslocamento e mobilidade, de meios de transportes e de uma cidadania não vivenciada no mundo da vida. Longe da ideia de vivermos em uma globalidade sem fronteiras, livre para a circulação de pessoas, bens e informações sem limites, a qual é imaginada na cidade mundo referenciada por Augé (2010), e, por sua vez, construída a partir das novas tecnologias da informação e comunicação, o estrangeiro lida constantemente com a realidade das cidades, carregada de contradições, diferenças, desigualdades, desconexões e circulações contidas.

Falar de estrangeiros da própria cidade ou da própria condição urbana é uma escolha que dialoga bem com a imposição de fronteiras que delimitam acessos e imobilidades, que delimitam o aceitável e o inadmissível, que criam a dicotomia do honesto e do vagabundo, do incluído e do excluído socialmente. Falar de estrangeiros é saber que o outro não desfruta do seu próprio lugar de morada na condição de cidadão, por mais conterrâneo que ele seja. Condiz, também, com a consciência de que os espaços urbanos não são livres, e sim territorializados e verticalizados. Falar de estrangeiros de nossa própria cidade é perceber que grandes centros, como o Rio de Janeiro, transformam-se constantemente enquanto cidades, instituindo cada vez mais e mais processos de exclusão e segregação. O estrangeiro da nossa própria cidade é determinado por diferenças étnico-culturais e/ou sociorraciais.

Assim, não só o migrante busca a mobilidade e cruza fronteiras ou tenta rompêlas, já que estas podem ser tanto de ordem física, de ordem linguística, política, econômica ou cultural, como as vê Augé (2010). Todo estrangeiro que admita, na sua diferença plural da urbanidade, uma estranheza em si e um espectro de uma realidade desigual e marginal, se vê bloqueado pelas fronteiras urbanas. Elas que se redesenham e que se reafirmam "constantemente sob formas enrijecidas, que funcionam como interditos e provocam exclusões" (AUGÉ, 2010, p. 23). O cotidiano dos estrangeiros é permeado por intensas tentativas de romper fronteiras.

A exclusão, o controle das fronteiras, a escolha de quem pode ou não cruzá-las e a admissão de quem entra e sai de determinado território, condiciona cidadãos e estrangeiros e, na perspectiva de Mezzadra (2012), trata de aspectos históricos chave da 


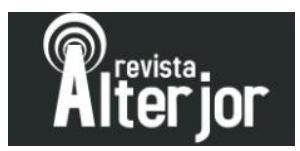

soberania nos regimes migratórios. As políticas de migração e de controle marcam a história da construção do capitalismo desde quando o primeiro navio negreiro cruzou o Oceano Atlântico. E a história, processualmente, continua. Em uma alusão à mesma condição devastadora do estrangeiro imigrante, que é proibido física e simbolicamente de cruzar fronteiras e interposto entre os subúrbios da indignidade e da ilegalidade, está o estrangeiro local, que, mesmo habitando e sendo gerado pela cidade, flutua também na indignidade dos acessos contidos e, por vezes, na ilegalidade, quando ameaça invadir territórios urbanos proibidos. As políticas de controle do estado se esvaem por critérios socioeconômicos e sociorraciais, que fragmentam a possibilidade de mobilidade e ocupação da cidade por pessoas e suas respectivas subjetividades marcadas, sobretudo, por diferenças.

É interessante pensar na abordagem que Kristeva (1994) traz sobre o estrangeiro para nós mesmos, quando ela afirma que o estrangeiro não vem de fora. Ele vem de nós mesmos e é o lado oculto de nossa própria identidade; sua figura surge na consciência de uma diferença e na (in)capacidade de aceitar formas de alteridade.

A dificuldade que a questão dos estrangeiros engendra estaria inteiramente contida no impasse da distinção que separa o cidadão do homem. Não é verdade que, para estabelecer os direitos próprios aos homens de uma civilização ou de uma nação - seja ela a mais racional e a mais conscienciosamente democrática -, somos obrigados a afastar esses direitos os não-cidadãos, isto é outros homens? Esse procedimento significa - e a sua consequência extrema - que somos mais ou menos homens à medida que somos mais ou menos cidadãos e que aquele que não é um cidadão não é inteiramente um homem (KRISTEVA, 1994, p. 102).

Menos cidadão e menos humano, portanto estrangeiros. Em uma ideia sempre negativa, este outro, o estrangeiro, é confundido com a figura de um invasor, de um inimigo em prontidão, ao dever do estado de combatê-lo. Impelido da cidade, impelido da vida e da expressão de seus fluxos e rastros, não baste a opressão sofrida, o estrangeiro de nossa própria cidade tem sua mobilidade rompida, sua liberdade questionada, o seu corpo vigiado e uma repressão engajada pelas políticas de segurança do estado. 


\section{Apartai-os em Copacabana}

A complexidade envolta no quadro panorâmico do estrangeiro, esse menos humano e menos cidadão, como um invasor, um refugiado e/ou um estranho, assume um formato inusitado nas praias da Zona Sul do Rio de Janeiro. Refiro-me aqui não ao estrangeiro turista de temporadas, que vem de outro país para dinamizar a economia da cidade maravilhosa e encher os bolsos do setor hoteleiro e das empresas turísticas. Este, aqui na cidade, é muito bem-vindo. Refiro-me não a estes que viajam o mundo e sim àqueles que "nunca saem dos seus lugares de nascimento" (LEMOS, 2009, p. 29).

O estrangeiro colocado em evidência ao se considerar bairros que circundam importantes praias do Rio de Janeiro, como Copacabana, Ipanema, Leblon e Leme, localizados na Zona Sul, área mais nobre da cidade.

O mapa nos mostra uma representação de pontos coloridos aludindo à ínfima quantidade de pretos e pardos - representados pelas cores vermelha e verde respectivamente - diante da estratosférica quantidade de brancos - representados pela cor azul - habitantes dos bairros da Zona Sul, segundo dados do Censo de 2010, realizado pelo Instituto Brasileiro de Geografia e Estatística (IBGE). A maior aglomeração de pretos e pardos condiz com áreas de favelas da Zona Sul, como o Morro Azul e a Rocinha. Os pontos verdes e vermelhos referem-se, portanto, aos estrangeiros locais. Refiro-me ao estrangeiro carioca, morador de favela, nascido na própria cidade em que vive. Este sim, aqui, expatriado, por ter-lhe negado o direito à cidade. Esta mesma cidade simbolicamente suntuosa como a pátria progenitora, que conforta - ou deveria confortar - sua subjetividade e supre - ou deveria suprir - todas as suas necessidades, acolhendo-lhe somente por ali tê-lo visto nascer, independentemente de qualquer diferença que se possa ter. Estrangeiro este apartado e negado desde o próprio parto, já que não nascera em cor e berço esplendidos. Este mesmo que, negro, cresce em meio ao racismo e à desigualdade e vivencia cotidianamente o apartheid urbano da segregação sociorracial. 


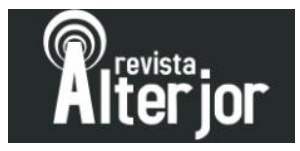

Quando o transporte coletivo, na sua função comum de interconectar, de fornecer mobilidade e de integrar pessoas a espaços - mesmo dentro de todas as limitações já mencionadas - passa a ser interceptado, exatamente com um objetivo avesso, impondo delimitação, fronteiras e inacessibilidade, há, nitidamente, a territorialização do espaço urbano e a instrumentalização de um serviço público ao alcance restringido por cor e classe social. Impõe-se, assim, verticalidades como "vetores de uma racionalidade superior e do discurso pragmático dos setores hegemônicos, criando um cotidiano obediente e disciplinado" (SANTOS, 1997, p. 286). O transporte público em contato operacionalizado com a segurança pública do estado torna-se, desse modo, mais um dispositivo de controle, aos moldes foucaultiano. Vigiase e se controla as fronteiras para que os fluxos migratórios dos estrangeiros locais, oriundos dos subúrbios e das periferias cariocas, não contrariem as leis de zoneamento ${ }^{4}$ da cidade, no sentido mais amplo que a expressão possa ter.

Delimitar é, para Raffestin (1993), isolar ou subtrair momentaneamente, manifestando poder em determinada área e, também, determinando relações espaciais de inclusões e exclusões. E delimitou-se a praia de Copacabana, mais uma vez, com o intercurso da segurança pública do estado interpondo barreiras da mobilidade e do acesso. Voltemos aos fatos do fim de semana dos dias 22 e 23 de agosto de 2015. Em um típico dia de sol, com uma típica motivação e objetivo de final de semana: ir à praia. Vários jovens de favelas se articularam e entraram em ônibus, cujas linhas ligam a Zona Norte à Zona Sul do Rio de Janeiro. Para uma tarde de lazer, nada mais do que trajes praianos. Sem camisas, de chinelos, de bermudas e, descompromissados com qualquer formalidade do cotidiano burocrático, os jovens também estavam sem documentos.

A lacuna do sem documentos que esses jovens inidentificáveis, de identidades esquecidas e relegadas apenas ao outro lado da cidade maravilhosa, deixaram foi pretexto para que 15 deles, todos negros e pobres, fossem detidos e banidos de desfrutarem da Praia de Copacabana, ao passarem por bloqueios realizados pela Polícia

\footnotetext{
4 "O zoneamento é de fundamental importância no planejamento de uma cidade, garantindo o seu desenvolvimento ordenado. Nele, o território municipal é dividido em partes - chamadas zonas - onde se definem, para cada uma delas, normas de uso e ocupação do solo” (RIO DE JANEIRO, 2013, p. 7).
} 


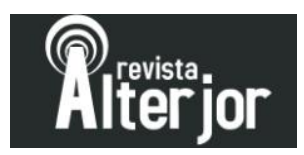

Militar do Estado do Rio de Janeiro (PMERJ), no bairro. Os ônibus em que os adolescentes estavam foram parados por policiais e os jovens com cara de suspeitos receberam a ordem do desembarque e tiveram que sair do veículo. A suspeição decretada pela cor da pele e o modo de se vestir se fundou na noção de periculosidade, que Foucault (2002) nos insere quando o indivíduo é considerado pela sociedade de acordo com suas virtualidades e não ao nível de suas ações. Todos os 15 jovens, assim, passaram por revistas e tiveram que abandonar o crime de ir à praia no fim de semana. Todos foram levados para o Centro Integrado de Atendimento à Criança e ao Adolescente (Ciaca). A somatória de apreensão de jovens totalizou 160 adolescentes detidos no fim de semana em questão, mesmo sem nenhum ato infracional ter sido registrado.

De acordo com o portal de notícias Extra, a polícia informou, em nota divulgada à imprensa, que as ações foram realizadas visando evitar flagrante de ato infracional e visando, também, proteger os menores em situação de risco. A justificativa usada pela corporação, entretanto, reflete a torpeza das políticas de vigília e controle do estado, guiadas por cor, origem e classe social, que legitimam a detenção de jovens negros e todas as proibições implícitas no cerceamento da liberdade deles. É evidente que os jovens não estavam em situação de risco, como alegou a polícia em nota, já que não havia nenhum contexto de exploração quando o plano era somente passar a tarde na praia. Entretanto, a situação de risco foi criada quando os garotos, mesmo sem cometerem nenhum ato infracional, ficaram sob custódia da Polícia Militar. O crime mesmo, grave e condenável de acordo com o artigo 230 do Estatuto da Criança e do Adolescente, foi "privar a criança ou o adolescente de sua liberdade, procedendo à sua apreensão sem estar em flagrante de ato infracional ou inexistindo ordem escrita da autoridade judiciária competente".

Após a série de detenções indevidas, um juiz da $1^{\text {a }}$ Vara da Infância, da Juventude e do Idoso da capital proibiu a PMERJ de apreender adolescentes sem que houvesse flagrante delito, segundo o portal de notícias Extra. O que se teve notícias após ao costumeiro - mas nem tão evidenciado - episódio das detenções e à decisão do juiz foi uma série de matérias jornalísticas, disseminando a criminalização da juventude 


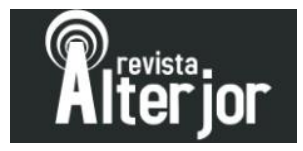

negra nas praias da Zona Sul da cidade, a partir da grande noticiabilidade de arruaças, furtos e roubos, associando os fatos à presença de jovens negros na área nobre do Rio de Janeiro. A indústria do medo, midiaticamente construída, mais uma vez, criou a demanda do negro pobre ligado ao banditismo e apavorou turistas e moradores da Zona Sul, ao falar de arrastões. Houve uma campanha midiática de criminalização da presença dos moradores da Zona Norte na praia e uma rejeição da população nobre carioca à decisão judicial da proibição das blitzen policiais.

Já que a polícia estava impedida de romper o deslocamento e acesso dos estrangeiros locais, os negros, pobres e favelados, às praias da Zona Sul, e o transporte coletivo deveria, por ordem judicial, continuar o fluxo das interconexões e exercer o seu papel elementar dessegregante, houve uma contrapartida antiarrastão mobilizada por um segmento indignado da população. 'Para enfrentar os 'arrastões' de fim de semana nas praias, moradores da Zona Sul, frequentadores de academias de artes marciais, 'resolveram organizar grupos antiarrastão, formados por lutadores' para combater" (FRANCISCO, 2003, p. 7) os novos casos. Esse trecho refere-se ao episódio de vários arrastões que aconteceram na cidade do Rio de Janeiro, em outubro de 1992, mas, pela similitude do que se passou, muito bem se aplica aos acontecimentos de setembro de 2015. Na ocasião de 1992, a explosão de arrastões incendiou a abordagem midiática e disseminou discussões sobre a proibição do acesso de pessoas da periferia às praias, resultando em políticas de restrição da prefeitura, junto às empresas do transporte coletivo, à Polícia Militar e à milícia dos lutadores indignados, que estabeleciam um apartheid evidente nas praias mais visadas da capital.

A milícia antiarrastão também foi mobilizada, em 2015, pelas redes sociais, por pessoas da classe média e alta e lutadores de academia que, em mensagens disseminadas na internet, convocaram os moradores da Zona Sul a se unirem contra os marginais e a omitirem qualquer registro e indícios que possibilitassem identificar os justiceiros ${ }^{5}$ em caso de morte e linchamento contra os arruaceiros. A primeira ação do grupo foi em

\footnotetext{
${ }^{5} \mathrm{O}$ termo justiceiros é equivocadamente empregado pelo discurso midiático, fazendo relação à ideia de fazer justiça com as próprias mãos, em se tratando de punir suspeitos. O termo é utilizado mesmo em meio a extrema violência, tal qual em casos de linchamento e de morte.
} 


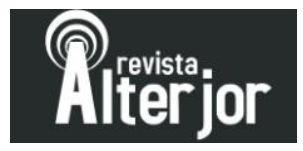

busca de "moleques de chinelo, com cara de quem não tem um real no bolso", como declarou um dos integrantes em matéria do portal de notícias Pragmatismo Político. Na Avenida Nossa Senhora de Copacabana, a milícia parou um ônibus da linha 472, que percorre o trajeto entre o bairro do Leme, na Zona Sul, e o bairro Triagem, na Zona Norte, e retirou um adolescente de dentro do ônibus, despontando chutes e socos no rapaz, ainda segundo o jornal.

\section{Considerações finais}

Contra todo excesso de controle e violência administrado nas tentativas de rompimento da mobilidade, da circulação e do acesso da população negra e pobre do Rio de Janeiro, realizou-se, na Praia do Arpoador, em Ipanema, um movimento que reuniu vários jovens ativistas oriundos de favelas da Zona Norte, no dia 4 de outubro de 2015. Intitulado de Farofaço, a manifestação, em meio ao alvoroço segregacionista expresso nas insurgências do estado, sua polícia militarizada e a população, fez jus ao uso pejorativo da expressão farofeiros, usada para inferiorizar moradores do subúrbio e da periferia da cidade quando, sem dinheiro para comprar comida na praia, pelos altos preços do comércio destinado a turistas, eles levam a própria alimentação de casa. Em um gesto simbólico de ocupação da cidade, os manifestantes fincaram várias bandeiras com o nome de favelas da Zona Norte na areia da praia.

A mobilização faz parte de uma luta comum de quem encontra fronteiras quando o assunto é o direito à vida na cidade, seja do estrangeiro de nossa própria cidade, seja do imigrante. É necessário que os próprios estrangeiros locais, estes mesmos que fazem da cidade um complexo de nomadismo - ideia trazida por Caiafa (2007) -, em seus rastros, fluxos e circulações, assumam o protagonismo de suas lutas.

Essas lutas, em todo caso, devem ser sempre consideradas não apenas na forma em que elas aparecem no interior da experiência migratória, mas também porque elas funcionam como referente essencial no desenvolvimento de uma nova teoria do 'racismo'. Esta teoria do racismo deve considerar a forma em que essas lutas são centrais nas 
relações sociais modeladas por mecanismos de racialização, permitindo assim que se enxergue a presença do migrante não apenas de uma forma 'vitimizada', mas em termos de uma subjetividade que se expressa em práticas inovadoras de resistência e luta (MEZZADRA, 2012, p. 85).

Inconformismo e resistência são forças simbólicas que, contra o infortúnio histórico da cidade verticalizada, reiteram a ocupação do espaço urbano em contato com subjetividades e a diversidade sociorracial e étnico-cultural. Os dispositivos de controle impregnados na vida urbana são utilizados em prol de efetivar uma política de estado racialista, que corrobora com o espírito do tempo das segregações, do individualismo e das dicotomias. Separa-se a sociedade, pela noção foucaultiana de periculosidade, entre pessoas de bem e pessoas que, sempre sob a lente do controle social e estatal, tem relação ou estão propensas ao crime e à criminalidade. De acordo com a perspectiva de Foucault (2002), há uma espécie de controle penal punitivo que - ao nível das virtualidades das ações referente a quem é negro e pobre - vai além do poder judiciário, perpassando por uma série de poderes laterais, à margem da justiça. A polícia - e, nesse caso, a milícia antiarrastão formada pelos lutadores de classe abastada - cumpre a função de vigilância e correção, junto a toda uma rede de instituições - escola, hospitais, empresas - que desvirtuam seu caráter elementar, para também corroborar com os dispositivos de controle e disciplinamento.

Até o transporte coletivo desagrega-se da sua função elementar de integração e passa a incorporar o panoptismo característico da nossa sociedade, sendo utilizado como mais um dispositivo. Determina-se quem pode e quem não pode se deslocar e até onde se pode ir. No olhar foucaultiano, o panoptismo se exerce individualmente em uma vigilância contínua, a partir da tríplice vigilância, controle e correção, como dimensão característica e fundamental das relações de poder que se instauram socialmente. A vigilância se dá "ao nível não do que se faz, mas do que se é; não do que se faz, mas do que se pode fazer. [...] a vigilância tende, cada vez mais, a individualizar o autor do ato, deixando de considerar a natureza jurídica, a qualificação penal do próprio ato" (FOUCAULT, 2002, p. 104). 


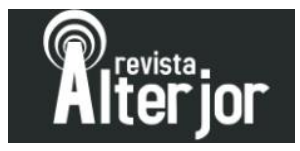

O fatídico episódio do apartheid social no transporte coletivo na cidade do Rio de Janeiro, seguido por uma massiva campanha midiática de criminalização da população negra, sobretudo, na intensa divulgação da relação dos arrastões com a presença dessa população nas praias, e o surgimento espontâneo de um grupo de ações racistas, opressoras e extremamente violentas deflagram o cenário de uma guerra não declarada, mas territorial. Na perspectiva de Deleuze \& Guattari (1997), o território, tido como objeto, é tomado como material de estratificação a se fazer ressoar. O Estado comporta uma guerra sob forma de instituições militares, que agem em uma hierarquia de poder que protege o centro, representado por quem está no alto. O ciclo se retroalimenta circularmente já que, do alto, tudo se vê, tudo se controla e o poder se constitui expandindo-se.

\section{Referências}

AUGÉ, M. Por uma antropologia da mobilidade. Maceió: EDUFAL: UNESP, 2010.

ÁVILA, E. Arrastões e assaltos assustam moradores e turistas no RJ. Portal G1. Rio de Janeiro, 21 set. 2015. Disponível em:

http://g1.globo.com/hora1/noticia/2015/09/arrastoes-e-assaltos-assustam-moradores-eturistas-no-rj.html. Acesso em: 20 out. 2015

BRASIL. Constituição da República Federativa do Brasil. Brasília, DF: Senado Federal: Centro Gráfico, 1988.

Estatuto da criança e do adolescente: Lei federal $\mathrm{n}^{\circ} 8069$, de 13 de julho de 1990. Rio de Janeiro: Imprensa Oficial, 2002.

CAIAFA, J. Aventura das cidades: ensaios e etnografias. Rio de Janeiro: Editora FGV, 2007.

DELEUZE, G.; GUATTARI, T. Mil Platôs: capitalismo e esquizofrenia, vol. 5. São Paulo: Editora 34, 1997.

FOUCAULT, M. As verdades e as formas jurídicas. 3.ed. Rio de Janeiro: Nau Editora, 2002.

FRANCISCO, D. Arrastão mediático e racismo no Rio de Janeiro. In: Congresso Brasileiro de Ciências da Comunicação, 16, 2003, Belo Horizonte-MG. Anais do Intercom. Belo Horizonte: 2003, p.1-15. Disponível em: < http://www.portcom.intercom.org.br/pdfs/1546838081826655035626085969225150106 37.pdf $>$. Acesso em: 31 out. 2015.

Revista ALTERJOR

Grupo de Estudos Alterjor: Jornalismo Popular e Alternativo (ECA-USP)

Ano 10 Volume 02 Edição $22 \quad$ Juho- Dezembro de 2020

Avenida Professor Lúcio Martins Rodrig̉ues, 443, Cidade Universitária, São Paulo, CEP: 05508-020 


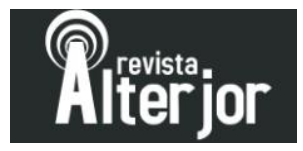

GONÇALVES, C. W. P. A globalização da natureza e a natureza da globalização. Rio de Janeiro: Civilização Brasileira, 2006.

HERINGER, C; BARROS, R. PM aborda ônibus e recolhe adolescentes a caminho das praias da Zona Sul do Rio. Extra. Rio de Janeiro, 07 set. 2015. Disponível em: < http://extra.globo.com/noticias/rio/pm-aborda-onibus-recolhe-adolescentes-caminhodas-praias-da-zona-sul-do-rio-17279753.html\#ixzz3qdh7q0sD>. Acesso em: 20 out. 2015 .

Justiça proíbe PM de apreender menores a caminho da praia sem flagrante. Extra. Rio de Janeiro, 10 set. 2015. Disponível em: <http://extra.globo.com/casos-depolicia/justica-proibe-pm-de-apreender-menores-caminho-da-praia-sem-flagrante7456393.html\#ixzz3qvVrK7PR>. Acesso em: 20 out. 2015.

KRISTEVA, J. Estrangeiros para nós mesmos. Trad. Maria Carlota C. Gomes. Rio de Janeiro: Rocco, 1994.

LEMOS, A. Cultura da Mobilidade. Revista Famecos, n. 40, dez. 2009. Disponível em: http://revistaseletronicas.pucrs.br/ojs/index.php/revistafamecos/article/viewFile/6314/45 89>. Acesso em: 10 out. 2015.

Lutadores de academia realizam 'blitz' para atacar suspeitos de assalto. Pragmatismo Político. Rio de Janeiro, 22 set. 2015. Disponível em:

http://www.pragmatismopolitico.com.br/2015/09/lutadores-de-academia-realizam-blitzpara-atacar-suspeitos-de-assalto.html>. Acesso em: 20 out. 2015.

MATELA, I. P. Reestruturação urbana neoliberal e as empresas de ônibus na cidade do Rio de Janeiro. Cadernos Metrópole. São Paulo, v.16, n.31, p.151-169, jun. 2014. Disponível em: <http://www.scielo.br/pdf/cm/v16n31/2236-9996-cm-16-31-0151.pdf>. Acesso em: 16 out. 2015

MEZZADRA, S. Multidão e migrações: a autonomia dos migrantes. Revista EcoPós. Rio de Janeiro, v.15, n.3, p.70-107, 2012. Disponível em: < https://revistas.ufrj.br/index.php/eco_pos/article/download/900/840>. Acesso em: 16 out. 2015

ONU. Declaração Universal dos Direitos Humanos. Disponível em: http://www.onubrasil.org.br/documentos_direitoshumanos.php>. Acesso: em 20 out. 2015.

RAFFESTIN, C. Por uma geografia do poder. Tradução: Maria Cecília França. São Paulo: Editora Ática, 1993.

RIO DE JANEIRO. Instrumentos do Plano Diretor: Lei de uso e ocupação do solo. Rio de Janeiro, 2013. Disponível em: http://www.rio.rj.gov.br/documents/91237/ddbd40f5fa89-40ff-b7e3-c2a9339f578d>. Acesso em: 5 nov. 2015.

SANTOS, M. A natureza do espaço: técnica e tempo, razão e emoção. 2. ed. São Paulo: Hucitec, 1997.

SCHUTZ - O estrangeiro, um ensaio em psicologia social. Revista espaço acadêmico. Maringá, v.10, n. 113, p.117-129, out. 2010. Disponível em: < 


\section{Anteior}

http://periodicos.uem.br/ojs/index.php/EspacoAcademico/article/view/11345 >. Acesso em: 20 out. 2015.

SILVA, M. N. A Favela como expressão de conflitos no espaço urbano do Rio de Janeiro: o exemplo da Zona Sul carioca. 2010. 154 f. Dissertação (Mestrado em Geografia) - Departamento de Geografia do Centro de Ciências Sociais, PUC-Rio, Rio de Janeiro, 2010.

Transporte passa a ser direito social na Constituição. Senado Notícias. Brasília, 09 set. 2015. Disponível em:

http://www12.senado.leg.br/noticias/materias/2015/09/09/transporte-passa-a-ser-direitosocial-na-constituicao>. Acesso em: 01 nov. 2015. 